\title{
PENERAPAN MANIPULASI LOCAL MASSAGE LOWER EXTREMITY (LMLE) TERHADAP PEMULIHAN DENYUT NADI PASCA AKTIVITAS PEMBELAJARAN PERMAINAN BOLA TANGAN
}

\author{
Ujang Rohman ${ }^{1}$, Sumardi ${ }^{2}$ \\ Program Studi Pendidikan Jasmani, Universitas PGRI Adi Buana Surabaya \\ ${ }^{1}$ ujang_roh64@unipasby.ac.id, 22sumardi@unipasby.ac.id
}

\begin{abstract}
Abstrak
Penelitian ini bertujuan untuk mengetahui pengaruh manipulasi Local Massage Lower Extremity (LMLE) terhadap pemulihan denyut nadi pasca aktivitas pembelajaran permainan bola tangan. Penelitian ini menggunakan metode eksperimen melalui pendekatan kuantitatif dengan disain penelitian ramdomized Pretest - Postest Design. Populasi adalah mahasiswa Pendidikan Jasmani Angkatan 2017, FKIP Universitas PGRI Adi Buana Surabaya dan sampel penelitian berjumlah 10 mahasiswa yang diambil secara proporsi (stratified proportional sampling). Teknik pengumpulan data menggunakan instrumen manipulasi masase olahraga dan analisis data menggunakan uji-t. Hasil analisis uji-t menunjukkan nilai uji-t dengan tarap nyata $(\alpha=0.05)$ serta derajat kebebasan $(\mathrm{dk}=9)$ ternyata nilai $\mathrm{t}$ hitung lebih besar dari nilai $\mathrm{t}$ tabel $(2.62 .>1.83)$ berarti penerapan manipulasi local massage lower extremity menunjukkan pengaruh yang berarti terhadap pemulihan denyut nadi pasca aktivitas pembelajaran permainan bola tangan. Hasil temuan penelitian menunjukkan bahwa pemberian manipulasi local massage lower extremity yang dilakukan selama 10-15 menit memberikan pengaruh yang berarti (signifikan) terhadap pemulihan denyut nadi (penurunan denyut nadi) setelah melakukan aktivitas fisik (olahraga) secara maksimal.
\end{abstract}

Kata Kunci: Local Massage, Denyut Nadi

\section{PENDAHULUAN}

Pola aktivitas dalam proses pembelajaran permainan bola tangan ada kecenderungan dilakukan dengan intensitas tinggi dan berubah-ubah. Oleh karena itu dalam proses pembelajaran permainan bola tangan dengan intensitas tinggi dan berubahubah ini akan terjadi gangguan kelelahan pada otot yang disebabkan adanya penumpukkan sisa metabolisme an-aerobik berupa asam laktat yang mengganggu sistem asam basa tubuh sehingga menghambat peredaran darah bila terlalu banyak menumpuk di otot.

Hal tersebut menurut Giriwijoya dan Sidik (2013) kelelahan fisik disebabkan karena kerja fisik atau kerja otot. Kerja otot ini akan menyebabkan penumpukan asam laktat sehingga menghambat glikolisis yang dapat menimbulkan kelelahan pada otot. Aktivitas fisik dengan intensitas tinggi dan berubah-ub ah antara sub-maksimal sampai maksimal 
dalam pembelajaran permainan bola tangan akan menyebabkan terjadinya perubahan fungsional tubuh pada mahasiswa baik yang bersifat responsif (sewaktu-waktu) maupun yang bersifat adaptif (tetap). Perubahan fungsional tubuh tersebut sebagai akibat terjadinya kontraksi otot secara an-aerobik yang membutuhkan penyediaan energi (adenosine triphosphate) melalui proses sistem asal laktat (lactit acid system) atau glikolisis an-aerobik. Proses ini berjalan secara simultan didalam tubuh saat melakukan aktivitas fisik (berolahraga). Selain itu aktivitas fisik dengan intensitas tinggi dan melelahkan akan meningkatkan jumlah leukosit dan netrofil saat sirkulasi maupun di dalam jaringan. Sedangkan aktivitas fisik yang berubah-ubah bersamaan berkurangnya aktivitas secara perlahan sistem fungsional tubuh akan beradaftasi kembali kekeadaan normal (homeostatis). Proses homeostatis tubuh membutuhkan waktu, sehingga semakin cepat waktu pemulihan, maka tubuh akan semakin cepat beradaftasi dalam proses pemulihannya untuk menghadapi aktivtas selanjutnya.

Kondisi tubuh dalam proses pembelajaran permainan bola tangan dampaknya akan membutuhkan energi (ATP) yang sangat dominan pada setiap mahasiswa, pasca setelah pembelajaran akan menimbulkan kelelahan yang dirasakan oleh tubuh, kerena terjadi penumpukkan asam laktat sehinga terjadi penurunan kondisi fisik. Agar tubuh lebih nyaman dan terhindar dari gangguan kelelahan sebagai akibat perubahan fungsional otot pada tubuh setelah melakukan aktivitas olahraga, maka salah satu alternatifnya dengan melakukan relaksasi otot melalui hidroterapi, spa dan masase olahraga (sport massage). Masase olahraga merupakan salah satu cara untuk merelaksasi otot-otot tubuh dan membuang rasa lelah setelah melakukan aktivitas olahraga karena dengan penerapan masase olahraga otot-otot pada tubuh digerakkan secara pasif dan dapat merangsang sistem saraf yang berpengaruh pada saat fase kontriksi dan dilatasi pembuluh darah. Hal ini seperti Kafrawi (2013 bahwa manipulasi masase olahraga dapat menurunkan 20-40\% konsentrasi kadar asam laktat yang menimbukan kenyamanan pada tubuh

Pemulihan kondisi fisik sangat berpengaruh terhadap aktivitas gerak tubuh seseorang, tidak terkecuali pada proses pembelajaran permainan bola tangan. Dalam pembelajaran permainan bola tangan tingkat kelelahan yang ditimbulkan dibutuhkan pemulihan kondisi fisik untuk dapat melakukan aktivitas lainnya dengan maksimal, Pemulihan kondisi fisik ada dua, yaitu pemulihan 
aktif dan pemulihan pasif. Pemulihan pasif yaitu suatu pemulihan tanpa adanya aktivitas fisik, yaitu diam, istirahat total (duduk, terlentang, tidur). Pengaruh pemulihan pasif, terhadap otot (kelelahan otot) agar dapat pulih kembali seperti semula. Prinsip dari pemulihan pasif, yaitu hampir sama dengan pemulihan aktif, yaitu mengembalikan lagi kondisi fisik seseorang agar seperti semula, serta memperbaiki kerusakan-kerusakan kecil pada otot. Cara untuk mempercepat masa pemulihan atau mempercepat penurunan denyut nadi setelah latihan, salah satunya dengan massage olahraga (sport massage). Massage olahraga adalah upaya masase dengan menggunakan teknik manipulasi yang bermacam-macam untuk memperbaiki dan mempertahankan kondisi tubuh serta menghilangkan kelainan-kelainan akibat olahraga yang ditimbulkan.

Salah satu usaha yang penting dalam mempersiapkan dan memelihara kondisi fisik yaitu dengan massage. Massage adalah satu unsur yang sangat penting pasca latihanlatihan bagi para atlet dengan efek rangsangan terhadap fungsional tubuh dan penyesuaiannya terhadap latihanlatihan yang makin lama menjadi semakin berat. Masase akan menimbulkan pengaruh fisiologis dan mekanis yang mendatangkan suatu relaksasi yang dapat mengurangi rasa sakit pada jaringan otot. Selain itu masase juga menimbulkan pengaruh secara psikologis yang dapat menimbulkan rasa percaya diri pada atlet untuk mempersiapkan fisik maupun mental atlet sebelum mengikuti pertandingan dan memaksimalkan potensi prestasi atlet, mempercepat proses pemulihan (recovery) serta mengurangi resiko terjadinya cedera maupun gangguan lain akibat aktivitas fisik dengan intensitas tinggi.

Masase pascaaktivitas fisik atau latihan dilakukan beberapa saat setelah beraktivitas atau latihan dengan tujuan mengurangi ketegangan otot dan meningkatkan pembuangan sisa metabolisme yang terjadi setelah kerja fisik dengan intensitas tinggi. Pada pembelajaran permainan bola tangan pemberian masage mempunyai peran dalam pemulihan terutama untuk membantu menurunkan denyut nadi setelah melakukan pembelajaran permainan bola tangan, khususnya pada bagian ekstrimitas bawah tubuh (lower extremity).

Hasil pengamatan selama berlangsungnya proses pembelajaran permainan bola tangan, diketahui bahwa saat proses pembelajaran yang diikuti mahasiswa rata-rata mengalami kelelahan sebagai akibat gangguan pada otot yang menyebabkan terjadinya penurunan kondisi fisik 
akibat dari penumpukkan asam laktat. Mengacu pada hal tersebut, permasalahan penelitian ini adalah mengenai pengaruh penerapan manipulasi local massage lower extremity terhadap pemulihan denyut nadi pasca aktivitas pembelajaran permainan bola tangan. Sedangkan tujuan penelitian ini untuk mengetahui mengenai dan mencari pengaruh penerapan manipulasi local massage lower extremity terhadap pemulihan denyut nadi pasca aktivitas fisik.

Manfaat yang diharapkan dari hasil temuan penelitian ini adalah memberikan informasi mengenai penanganan baik secara pencegahan maupun pengobatan dalam dalam proses pemulihan denyut nadi melalui terapi manipulasi local massage lower extremity pasca melakukan aktivitas olahraga umumnya dan khususnya pasa pembelajaran pernainan bola tangan khususnya.

\section{METODE PENELITIAN}

Penelitian ini menggunakan metode eksperimen melalui pendekatan kuantitatif yang terstruktur dan sistimatis dalam bentuk tampilan data-data yang diperoleh dari hasil tes dan pengukuran dengan disain penelitian menggunakan ramdomized Pretest Postest Design. Salah satu ciri utama penelitian eksperimen adalah adanya perlakuan (treatment) yang dikenekan kepada subjek atau objek penelitian. Dalam penelitian eksperimen, seorang peneliti sejauh mungkin harus dapat memastikan bahwa variasi atau perubahan yang terjadi pada variabel terikat benar-benar disebabkan oleh adanya manipulasi pada variabel bebas. Hal inilah yang kemudian disebut validitas internal. Dalam kaitan ini, mekanisme kontrol menjadi sesuatu yang sangat penting (Maksum, 2012).

Populasi penelitian adalah mahasiswa Pendidikan Jasmani, FKIP Universitas PGRI Adi Buana Surabaya, sedangkan sampel penelitian adalah mahasiswa angkatan 2017 yang berjumlah 140 orang terdiri dari kelas A, B, C, D dan E. Pengambilan sampel menggunakan teknik proporsi berdasarkan stratified proportional sampling dengan cara: 1) menghitung jumlah persentase perkelas, 2) menentukan banyaknya sampel, 3) memilih sampel secara acak (random) yang akan dijadikan sampel penelitian.

Berdasarkan hal tersebut didapatkan sebanyak 10 mahasiswa yang berasal dari setiap kelas berjumlah 2 mahasiswa. Teknik pengumpulan data menggunakan instrumen manipulasi masase olahraga (sport massage) pada bagian ekstremitas bawah yang meliputi otot-otot pada bagian gelang pinggul, tungkai atas (paha), tungkai bawah (betis) adan otot-otot bagian kaki selama 10-15 
menit. Pengumpulan data dilakukan pada mahasiswa setelah melakukan pembelajaran permainan bola tangan. Teknik analisis data melalui dua tahapan yaitu pertama uji normalitas dan homogenitas data dan kedua uji hipotesis (uji-t) untuk mengetahui pengaruh manipulasi massage lokal ektremitas bawah terhadap pemulihan denyut nadi pasca aktivitas pembelajaran permainan bola tangan.

\section{HASIL DAN PEMBAHASAN}

\section{Hasil Penelitian}

Mengacu pada hasil tes manipulasi local massage lower extremity, analisis data dalam penelitian ini meliputi tahapan uji normalitas dan homogenitas data serta dilanjutkan uji-t. Hasil analisis uji normalitas dan homogenitas data disajikan pada tabel berikut.

Tabel 1 Data Uji Normalitas dan Homogenitas

\begin{tabular}{llllc}
\hline $\mathrm{N}$ & \multicolumn{1}{c}{ Variabel } & Uji $\chi^{2}$ & $\mathrm{Uji} F$ & Ket. \\
\hline 10 & Pemulihan & 0.754 & 0.831 & $\mathrm{Sig}$, \\
& Denyut Nadi & & & 0,05 \\
& Pasca & & & \\
& Aktivitas & & & \\
& Fisik & & & \\
\hline
\end{tabular}

Tabel 1 menunjukkan nilai chisquare $\left(\chi^{2}\right)$ dengan tarap nyata $(\alpha)$ sebesar 0.05 serta derajat kebebasan (dk) sebesar 9 hasilnya nilai $\chi^{2}$ hitung sebesar 0.754 dan nilai $\chi^{2}$ tabel sebesar 16.9 ternyata nilai $\chi^{2}$ hitung lebih kecil dari nilai $\chi^{2}$ tabel $(0.754<16.9)$ hal ini berarti distribusi data tes manipulasi local massage lower extremity dinyatakan normal. Sedangkan nilai varian $\mathrm{F}$ hitung hasil uji homogenitas data dengan tarap nyata $(\alpha)$ sebesar 0.05 serta derajat kebebasan (dk) pembilang 9, penyebut 9 (9:9), hasilnya nilai $F$ hitung lebih kecil dari nilai $\mathrm{F}$ tabel $(0.831<3.18)$ hal ini berarti varian data tes local massage lower extremity dinyatakan homogen.

Berdasarkan hasil uji normalitas dan homogenitas data tersebut, selanjutkanya dilakukan.uji hipotesis untuk mengetahui dan membuktikan pengaruh manipulasi local massage lower extremity terhadap pemulihan denyut nadi pasca aktivitas fisik. Untuk uji hipotesis kriteria pengujian mengunakan analisis statistik uji-t. Hasil penghitungan analisis uji-t pemulihan denyut nadi disajikan pada tabel berikut.

Tabel 2 Uji Hipotesis Variabel X terhadap Y

\begin{tabular}{lllll}
\hline \multirow{2}{N}{} & Variabel & \multicolumn{2}{c}{ Uji Hipotesis } & \multirow{2}{*}{ Ket. } \\
\cline { 3 - 4 } & & thitung & $\mathrm{t}_{\text {tabel }}$ & \\
\hline 10 & Pemulihan & & & \\
& $\begin{array}{l}\text { Denyut } \\
\text { Nadi Pasca }\end{array}$ & 2.62 & 1.83 & Signifikan \\
& Aktivitas & & & \\
& Fisik & & & \\
\hline
\end{tabular}

Tabel 2 menunjukkan nilai uji-t dengan tarap nyata $(\alpha=0.05)$ serta derajat kebebasan $(\mathrm{dk}=9)$ ternyata nilai $\mathrm{t}$ hitung lebih besar dari nilai $\mathrm{t}$ tabel (2.62. > 1.83) berarti penerapan 
manipulasi local massage lower extremity menunjukkan pengaruh yang berarti terhadap pemulihan denyut nadi pasca aktivitas pembelajaran permainan bola tangan. Temuan penelitian ini adalah pemberian manipulasi local massage lower extremity selama 10-15 menit memberikan pengaruh yang berarti (signifikan) terhadap pemulihan denyut nadi (penurunan denyut nadi) setelah melakukan aktivitas fisik maksimal.

\section{Pembahasan}

Berdasarkan analisis data, temuan hasil penelitan bahwa lokal manipulasi local massage lower ektremity memberikan pengaruh secara signifikan terhadap pemulihan denyut nadi pasca melakukan aktivitas pembalajaran permainan bola tangan dengan nilai $t$ hitung sebesar 2.62 dan $t$ tabel sebesar 1.83 (2.62 > 1.83), artinya pemberian manipulasi lokal masase pada bagian ekstremitas bawah memberikan pengaruh terhadap pemulihan denyut nadi pasca aktivitas olahraga, karena dengan pemberian manipulasi masase pada bagian ekstremitas bawah akan terjadi respon pada otot sehingga menimbulkan proses pemulihan dalam bentuk penurunan denyut nadi. Dalam hal ini sesuai dengan hasil penelitian Hermawan (2015) bahwa sport massage secara signifikan ada pengaruhnya terhadap penurunan denyut nadi artinya sport massage akan mengalami perubahan denyut nadi. Selain itu menurut Purnomo (2014) pemberian sport massage akan mempelancar alirah darah, merileksasikan otot dan merangsang sistem saraf pada tubuh sehingga secara fungsional organ tubuh akan kembali bekerja normal. Efek yang paling dominan diberikannya manipulasi sport message pasca aktivitas fisik terutama terjadinya pelebaran pemubuluh darah yang menyebabkan aliran darah akan semakin lancar dan pemulihan denyut nadi akan cepat normal kembali.

Aktivitas fisik yang dilakukan dengan intesitas sub-maksimal atau maksimal akan menyebabkan semakin besarnya penumpukkan kadar asam laktat sehingga akan menghambat glikolisis yang berakibat timbulnya kelelahan pada jaringan otot. Menurut Harahap dan Sagala ( 2017). Asam laktat merupakan produk hasil metabolisme karbohidrat tanpa menggunakan oksigen (metabolisme anaerob). Asam laktat diproduksi di sel otot saat suplai oksigen tidak mencukupi untuk menunjang produksi energi. Penumpukan asam laktat terjadi setelah melakukan aktifitas fisik selama 1.5 - 2 menit akan menghambat glikolisis, sehingga timbul kelelahan otot. Kelelahan otot yang ditimbulkan pasca aktivitas fisik (berolahraga) tersebut untuk mempercepat pemulihannya, salah 
satunya dengan diberi manipulasi masase atau dalam pemulihannya dilakukan dengan cara manipulasi masase. Pemberian manipulasi sport massage selama 10-15 menit memberikan pengaruh signifikan terhadap penurunan jumlah kadar laktat darah setelah melakukan aktifitas fisik maksimal. Hal ini sesuai dengan dijelaskan Joesoef (2015), bahwa masase olahraga adalah teknik menyentuhdengan meneken bagian bagian tubuh untukmempengaruhi syaraf dan otot-otot agar mengendur sehingga dapat bekerja secara maksimal sesuai dengan fungsinya, dengan Masase olahraga sirkulasi darah pada otot dan organ menjadi lancar dan aliran limpa menjadi teratur sehingga dapat. mengembalikan kebugaran tubuh atau mengembalikan kondisi tubuh seperti sedia kala atau dalam keadaan normal (homeostatis)

Temuan hasil penelitian menujukkan bahwa penerapan manipulasi local massage lower extremity menunjukkan pengaruh yang berarti terhadap pemulihan denyut nadi pasca pembelajaran permainan bola tangan. Pemulihan denyut nadi sebagai akibat dari manipulasi local massage lower extremity pasca aktivitas fisik (olahraga) akan mempercepat metabolisme asam laktat yang dikonferen kembali menjadi energi untuk digunakan dalam aktivitas fisik selanjutnya.

\section{SIMPULAN}

Berdasarkan analisis data serta pengujian hipotesis, maka dapat ditarik simpulan bahwa penerapan manipuasi local massage lower extremity memberikan pengaruh yang berarti terhadap pemulihan denyut nadi pasca pembelajaran permainan bola tangan. Hal ini diketahui dari hasil analisis menunjukkan nilai uji-t dengan tarap nyata $(\alpha=0.05)$ serta derajat kebebasan $(\mathrm{dk}=9)$ ternyata nilai $\mathrm{t}$ hitung lebih besar dari nilai $t$ tabel (2.62. > 1.83). Hasil analisis ini membuktikan bahwa penerapan manipulasi local massage lower extremity menunjukkan pengaruh yang berarti terhadap pemulihan denyut nadi pasca aktivitas pembelajaran permainan bola tangan. Hasil temuan penelitian adalah pemberian manipulasi local massage lower extremity selama 10-15 menit memberikan pengaruh yang berarti (signifikan) terhadap pemulihan denyut nadi (penurunan denyut nadi) setelah melakukan aktivitas fisik maksimal.

\section{DAFTAR PUSTAKA}

Bambang Priyonoadi. (2008). Sport Massage (Masase Olahrga). Yogyakarta: FIK UNY.

Burnley DE, Angela NO, Sharp RL, BailerSW, Alekel DL, 2010. Impact ofProtein Suplements on MuscleRecovery After Exercise- 
InducedMuscle Soreness. Journal ExerciseScience Fitness. 8: 89-96.

Clarson PM, Hubal MJ, 2008. ExerciseInduced Muscle Damage in Humans.Journal Physiology Medical Rehabilitation. 81 (2) 5269.

Giriwijoyo, H.Y.S Santoso dan DIdik Zafar Sidik. 2012. Ilmu Kesehatan Olahraga. Bandung: PT Remaja Rosdakarya.

Giriwijoyo, S. dan Sidik, Dikdik Zafar., 2013. Ilmu Faal Olahraga (Fisiologi Olahraga): Fungsi Tubuh Manusia Pada Olahraga untuk Kesehatan dan Prestasi. Bandung: Remaja Rosdakar.

Hilbert, J. E., G. A. Sforzo and T. Swensen 2003. The effects of massage on elayed onset muscle soreness. British Journal of Sports Medicine. 37 (1) 72-86.

Kafrawi, Fatkhur Rohman. 2001. Pengruh Pemberian Penguluran dan Massase OlahragaTerhadap Pencapaian Pulih Asal. Tesis. Tidak Dipublikasikan Surabaya: PPs Universitas Negeri Surabaya
Moraska, A. 2005. Sports massage. The Journal of Sports Medicine and Physical Fitness. 45 (2) 370-388.

Maksum, Ali. 2012. Metodelogi Penelitian. Surabaya: Unesa University Press.

Novita Sari Harahap., Nila Sari Rosenta Sagala. 2017. Pengaruh Pemberian Manipulasi Sport Massageterhadap Kadar Asam Laktat Darah Setelah Melakukan Aktivitas Fisik Maksimal. Jurnal Kesehatan dan Olahraga, Prodi Ilmu Keolahragaan, FIK Unimed Medan, 1 (2), 11-21.

Roepajadi, Joesoef, dkk .2015. Masase Olahraga. Edisi Pertama.Surabaya: Unesa University Press.

Sidik, didik zafar, dkk. 2012. Penerapan Complex Training Terhadap Peningkatan Kemampuan Anaerobik. Jurnal Iptek Olahraga. Volume. 14 (2): Hal 124-142.

Syaifuddin (2011). Pengantar Anatomi dan Fisiologi. Yogyakarta: EGC. 